\title{
Risk factors for lower airway bacterial colonization in chronic bronchitis
}

\author{
E. Monsó, A. Rosell, G. Bonet, J. Manterola, P.J. Cardona, J. Ruiz, J. Morera
}

Risk factors for lower airway bacterial colonization in chronic bronchitis. E. Monsó, A. Rosell, G. Bonet, J. Manterola, P.J. Cardona, J. Ruiz, J. Morera. (C)ERS Journals Ltd 1999. ABSTRACT: The aim of this study was to determine the prevalence and risk factors for lower airway bacterial colonization (LABC) in stable chronic bronchitis (CB).

Forty-one outpatients with CB were enrolled in the study (age 63.8 \pm 9.1 yrs (mean \pm SD); forced expiratory volume in one second (FEV1)/forced vital capacity (FVC) 62.8 \pm 11.2 ; current/former smokers $24 / 17$ ). All patients had normal chest radiographs and an indication for performing fibreoptic bronchoscopy (pulmonary nodule, remote haemoptysis). The protected specimen brush (PSB) was used for bacterial sampling, and concentrations $\geq 1,000$ colony-forming units $(\mathrm{cfu}) \cdot \mathrm{mL}^{-1}$ were considered positive for $\mathrm{LABC}$. The repeatability of the procedure in $\mathrm{CB}$ was assessed in a random subsample of 18 subjects.

A $72.2 \%$ quantitative agreement was found in the repeatability assessment of the PSB technique. Positive PSB cultures, obtained in 9 out of $41(22 \%)$ patients, mainly yielded Haemophilus influenzae. The logistic regression model, used to determine which variables were related to colonization, showed that $L A B C$ was associated with current smoking (odds ratio (OR) 9.83, confidence interval (CI) 1.16-83.20) and low FVC (OR 0.73, CI 0.65-0.81). Age and FEV1 were not related to LABC.

It was concluded that the prevalence of $L A B C$ in stable $C B$ is high (22\%), and current smoking is an important risk factor.

Eur Respir J 1999; 13: 338-342.
Serveis de Pneumologia i Microbiologia, Hospital Germans Trias i Pujol, Badalona, Catalonia, Spain.

Correspondence: E. Monsó

Servei de Pneumologia

Hospital Germans Trias i Pujol

Ap correus 72

08916 Badalona

Catalonia

Spain

Fax: 34934978843

Keywords: Chronic bronchitis

lower airway bacterial colonization protected specimen brush

risk factors

repeatability

smoking

Received: October 271997

Accepted after revision July 131998

Funded by FISss 94/0608.
Nontypeable Haemophilus influenzae, Streptococcus pneumoniae and Moraxella catarrhalis are commonly related to the exacerbations of chronic bronchitis (CB) [1]. In exacerbated $\mathrm{CB}$, lower airway microbiological sampling, performed following procedures that preclude contamination from oropharyngeal flora, yields positive bacterial cultures in $50-75 \%$ of cases [2-5]. However, $25 \%$ of such patients also give positive cultures when sampled in a clinically stable situation, showing that lower airway bacterial colonization (LABC) is common in CB [4]. The causes of LABC are poorly understood.

A cross-sectional study of 41 outpatients with stable CB was conducted using the protected specimen brush (PSB) technique $[6,7]$, in order to determine the prevalence of LABC and the risk factors associated with such colonization in this population.

\section{Materials and methods}

\section{Population}

A series of 41 stable CB outpatients were defined as having chronic phlegm ( $>3$ months $\cdot \mathrm{yr}^{-1}$ for $\geq 2 \mathrm{yrs}$ ) and normal or near-normal (pulmonary nodule $<3 \mathrm{~cm}$ diameter) chest radiographs, with no acute lung disease [8]. Only patients with no changes in the volume or appearance of sputum or level of dyspnoea in the previous 15 days were

For editorial comments see page 233 considered to have stable CB. Patients who had been admitted to hospital within the last 6 months, who had been treated with antibiotics during the month prior to microbiological sampling, with clinical or radiological signs suggestive of bronchiectasis or who had alveolar or interstitial opacities on a chest radiograph were not included. Patients with a history of diagnosed bronchial asthma or positive reversibility tests were also excluded. All patients meeting the inclusion criteria who had been examined with fibreoptic bronchoscopy (indication: pulmonary nodule $<3 \mathrm{~cm}$ diameter or remote haemoptysis) over a 1-yr period were included in a cohort study on the effect of bronchial colonization on lung health (age 63.8 \pm 9.1 yrs (mean $\pm \mathrm{SD}$ ), height $164.3 \pm 6.5 \mathrm{~cm}$, all males, current/former smokers 24/17). This paper describes the findings of the initial cross-sectional phase of this cohort study.

Forced spirometry was performed in all patients using a dry spirometer (Micro Medical, Rochester, UK) $1 \mathrm{~h}$ before premedication and fibreoptic bronchoscopy. The highest values of the forced expiratory volume in one second (FEV1) and forced vital capacity (FVC) recorded from three technically acceptable manoeuvres with $<5 \%$ variation between them were considered.

\section{Microbiological sampling}

Premedication, with $0.01 \mathrm{mg} \cdot \mathrm{kg}^{-1}$ intramuscular atropine, was administered and topical anaesthesia was achieved by nebulization of $5 \mathrm{~mL} \mathrm{4 \%} \mathrm{lidocaine} \mathrm{through} \mathrm{a}$ 
mouthpiece over $15 \mathrm{~min}$. No topical anaesthetics were injected through the inner channel of the fibreoptic bronchoscope and suction was not used before PSB sampling. Intranasal anaesthesia was achieved by instillation of 2 $\mathrm{mL} 4 \%$ lidocaine. A bronchoscope was inserted through a nasal fossa, the tip was positioned in the trachea and microbiological sampling was performed as described elsewhere [4]. In brief, a PSB (Mill-Rose Laboratories, Mentor, $\mathrm{OH}, \mathrm{USA}$ ) was inserted through the inner suction channel and advanced under direct vision to the level of a right lower lobe segmentary/subsegmentary bronchus, where the sample was obtained.

\section{Microbiological processing}

Specimens were transported to the laboratory within 15 min of collection and $0.1-\mathrm{mL}$ aliquots of the original suspension were placed on agar plates for aerobic and anaerobic culture (MacConkey agar; 5\% defibrinated sheep blood in Columbia base; $5 \%$ defibrinated sheep blood in Columbia base, colistin and nalidixic acid; chocolate agar; alpha-charcoal yeast extract (CYE) selective legionella medium; Saboraud medium; Wilkins-Chalgren laked blood agar; and Wilkins-Chalgren laked blood agar, vancomycin and kanamycin). Accepted laboratory methods were used for bacterial identification and susceptibility testing [9]. A bacterial count $\geq 1,000$ colony-forming units (cfu). $\mathrm{mL}^{-1}$ was considered positive.

\section{Repeatability of the protected specimen brush technique in chronic bronchitis}

To assess, in CB, the repeatability of the PSB technique, two PSB samples were obtained from the same lung area in 18 patients selected at random. Quantitative and qualitative agreement of the paired samples were assessed. Results obtained from the second PSB sample were only considered for the repeatability analysis.

\section{Statistical analysis}

All the data were analysed using the SAS 6.04 statistical package (SAS Institute, Cary, NC, USA). Results are expressed as means and standard deviations unless otherwise stated. A logistic regression model was constructed in order to assess the risk factors for $\mathrm{LABC}$ in $\mathrm{CB}$, taking into account age, smoking and lung function (FEV1, FVC, FEV1/FVC) as independent variables. For this analysis, a unit of variation in a lung function parameter was defined as a $10 \%$ change in the value of that parameter. Results were considered statistically significant when $\mathrm{p}<0.05$.

\section{Results}

\section{Prevalence of lower airway bacterial colonization}

The 41 patients with stable CB had, in most cases, normal lung function (11 (26.8\%) patients) or light/moderate obstructive ventilatory patterns (FEV1 $\geq 50 \%$ pred, 25 pa- tients $(61.0 \%)$ ), as revealed by forced spirometry (FVC $91.0 \pm 18.9 \%$ predicted; FEV1 $74.6 \pm 23.7 \%$ pred; FEV1/ FVC $62.8 \pm 11.2$ ). Positive PSB cultures were obtained in nine $(22.0 \%)$ of the 41 patients. Nontypeable H. influenzae was cultured from five samples, Streptococcus viridans group from two, Proteus mirabilis from one and Neisseria spp. from one. Four samples were positive for a second bacterium (S. pneumoniae in two cases, $S$. viridans group in one and Corynebacterium spp. in one case). In three cases, the PSB culture yielded low concentrations $(<1,000$ $\left.\mathrm{cfu} \cdot \mathrm{mL}^{-1}\right)$ of $S$. viridans group and Neisseria spp. and these results were considered negative (table 1).

\section{Repeatability of the protected specimen brush technique}

Using the $1,000 \mathrm{cfu} \cdot \mathrm{mL}^{-1}$ threshold recommended to identify a positive bacteriological result, quantitative agreement was found in 13/18 (72.2\%) cases, a level similar to that described for pneumonia. Qualitative agreement was lower, however, as only $9 / 19(47.4 \%)$ bacterial species recovered grew in the two consecutive samples (table 2). From these results, it was considered that the quantitative repeatability of the PSB technique in $\mathrm{CB}$ is equivalent to the repeatability of the procedure in pneumonia, although the qualitative repeatability of the procedure is lower.

\section{Risk factors for lower airway bacterial colonization}

The logistic regression model used to determine which variables are predictors of $\mathrm{LABC}$ in stable $\mathrm{CB}$ showed that current smoking, as opposed to former smoking, was associated with LABC (odds ratio (OR) 9.83, confidence interval (CI) 1.16-83.20). A slight but statistically significant association between low FVC, and LABC was also found (OR 0.73, CI 0.65-0.81). None of the other dependent variables included in the model (age, FEV1 or FEV1/ FVC) showed any additional association with LABC (table 3).

Table 1. - Results of protected specimen brush culture in chronic bronchitis $(n=41)$

\begin{tabular}{|c|c|c|}
\hline Case No. & Bacteria & $\mathrm{cfu} \cdot \mathrm{mL}^{-1}$ \\
\hline \multicolumn{3}{|c|}{ Positive $\left(>1000 \mathrm{cfu} \cdot \mathrm{mL}^{-1}\right)$} \\
\hline 1 & Haemophilus influenzae & 2000 \\
\hline \multirow[t]{2}{*}{2} & H. influenzae & 20000 \\
\hline & Streptococcus pneumoniae & 1000 \\
\hline 3 & H. influenzae & 10000 \\
\hline 4 & Neisseria spp. & 4000 \\
\hline \multirow[t]{2}{*}{5} & H. influenzae & 50000 \\
\hline & S. pneumoniae & 5000 \\
\hline 6 & Streptococcus viridans group & 2000 \\
\hline \multirow[t]{2}{*}{7} & Proteus mirabilis & 4000 \\
\hline & $S$. viridans group & 5000 \\
\hline 8 & H. influenzae & 8000 \\
\hline \multirow[t]{2}{*}{9} & S. viridans group & 3000 \\
\hline & Corynebacterium spp. & 1000 \\
\hline \multicolumn{3}{|c|}{ Negative $\left(<1000 \mathrm{cfu} \cdot \mathrm{mL}^{-1}\right)(\mathrm{n}=32)$} \\
\hline \multirow[t]{2}{*}{10} & S. viridans group & $<100$ \\
\hline & Neisseria spp. & $<100$ \\
\hline 11 & S. viridans group & 400 \\
\hline 12 & S. viridans group & $<100$ \\
\hline $13-41$ & Sterile & - \\
\hline
\end{tabular}

cfu: colony-forming units. 
Table 2. - Repeatability of protected specimen brush cul-ture in chronic bronchitis $(n=18)$

\begin{tabular}{|c|c|c|c|}
\hline \multirow[b]{2}{*}{ Case No. } & \multirow[b]{2}{*}{ Bacteria } & \multicolumn{2}{|c|}{ Sample culture $\mathrm{cfu} \cdot \mathrm{mL}^{-1}$} \\
\hline & & 1 & 2 \\
\hline \multirow[t]{3}{*}{1} & Haemophilus influenzae & 2000 & 3500 \\
\hline & Moraxella catarrhalis & 500 & 0 \\
\hline & Streptococcus pneumoniae & 500 & 3500 \\
\hline \multirow[t]{2}{*}{2} & H. influenzae & 20000 & 12500 \\
\hline & S. pneumoniae & 1000 & 0 \\
\hline 3 & H. influenzae & 10000 & 3000 \\
\hline 4 & Neisseria spp. & 4000 & 0 \\
\hline \multirow[t]{2}{*}{5} & H. influenzae & 50000 & 0 \\
\hline & S. pneumoniae & 5000 & 0 \\
\hline 6 & Streptococcus viridans group & 2000 & 5000 \\
\hline 8 & H. influenzae & 8000 & 3000 \\
\hline \multirow[t]{3}{*}{10} & S. viridans group & $<100$ & $<100$ \\
\hline & Neisseria spp. & $<100$ & $<100$ \\
\hline & Staphylococcus aureus & 0 & $<100$ \\
\hline 11 & S. viridans group & 400 & 100 \\
\hline 12 & $S$. viridans group & $<100$ & 0 \\
\hline 13 & S. pneumoniae & 0 & 5000 \\
\hline 14 & Sterile & 0 & 0 \\
\hline 15 & Sterile & 0 & 0 \\
\hline 16 & H. influenzae & 0 & 100,000 \\
\hline 17 & Sterile & 0 & 0 \\
\hline 18 & S. viridans group & 0 & 8000 \\
\hline 19 & Sterile & 0 & 0 \\
\hline 20 & Sterile & 0 & 0 \\
\hline
\end{tabular}

cfu: colony-forming units.

\section{Discussion}

This PSB study found LABC in $22 \%$ of clinically stable CB outpatients, mainly attributable to nontypeable $H$. influenzae, and demonstrated that current smoking is a risk factor for $\mathrm{LABC}$.

Nontypeable $H$. influenzae, S. pneumoniae and $M$. catarrhalis are commonly found in sputum cultures from patients with CB [10-14]. However, as sputum samples can be contaminated with oropharyngeal secretions, they are of limited value in discriminating between infection, colonization and oropharyngeal contamination $[15,16]$. The PSB sampling technique described by WIMBERLEY and coworkers $[6,7]$ permits the culture of micro-organisms, in lower respiratory secretions without contamination by upper respiratory airway flora. This technique has been shown to be highly accurate for the bacteriological diagnosis of pneumonia in patients who have not received antibiotics in the period prior to sampling $[17,18]$. In such patients, repeated PSB samples show quantitative agreement when

Table 3. - Predictors of lower airway bronchial colonization

\begin{tabular}{lccc}
\hline Dependent variable & SE & OR & CI \\
\hline Age & - & - & NS \\
Current smoking & 0.63 & 9.83 & $1.16-83.2$ \\
FVC \% pred & -0.33 & 0.73 & $0.65-0.81$ \\
FEV1 \% pred & - & - & NS \\
FEV1/FVC & - & - & NS \\
\hline
\end{tabular}

SE: standardized estimate; OR: odds ratio; CI: confidence interval; FVC: forced vital capacity; FEV1: forced expiratory volume in one second. a threshold of $1,000 \mathrm{cfu} \cdot \mathrm{mL}^{-1}$ is considered to indicate a positive result. The distinction between the presence or absence of infection based on this diagnostic threshold is only moderately affected by the variability in the measurement, as shown by the $80-90 \%$ quantitative repeatability of PSB sampling reported in several studies [19-21]. Because the repeatability of this technique in stable CB has not been previously assessed, to the authors' knowledge, paired PSB samples were obtained from the same lung area in a subsample of 18 patients, using the $1,000 \mathrm{cfu}$. $\mathrm{mL}^{-1}$ threshold to identify a positive bacteriological result. Quantitative agreement was found in $72.2 \%$ of the paired cases, from which it can be considered that the quantitative repeatability of PSB in $\mathrm{CB}$ is equivalent to that in pneumonia.

In the present study nontypeable $H$. influenzae was the most common pathogen identified in the colonized lower airways of stable $\mathrm{CB}$ outpatients. $H$. influenzae is often found in the respiratory secretions of $\mathrm{CB}$ patients, and can persist in lower airway secretions in spite of serum antibodies against the bacterium [22]. Furthermore, H. influenzae strains cultured from lower airway secretions during an exacerbation are often found in the respiratory secretions when the disease is stable, regardless of the antibiotic treatments prescribed [23, 24]. Microbial persistence of $S$. pneumoniae in lower airway secretions has also been related to the clinical exacerbations that appear when $\mathrm{CB}$ patients are followed over time [25].

The present study demonstrates that current smoking is a predictor of $\mathrm{LABC}$ in stable $\mathrm{CB}$ (OR 9.83). An association between current smoking and $\mathrm{LABC}$ was first suggested by IRWIN et al. [26] in a study of tracheobronchial colonization, using transtracheal aspiration. They found 
positive results in $50 \%$ of the studied smokers, mainly due to the $S$. viridans group. This effect of current smoking on LABC may be related to the impairment of lower airway clearance described in smokers. Current smoking slows the mucociliary clearance rate in asymptomatic smokers [27] and this effect increases when CB appears [28, 29]. $\mathrm{LABC}$ is related not only to tracheobronchial clearance, but also to the appearance of changes in bronchial mucosa that encourage bacterial colonization [30]. RIISE et al. [31], in a study of the association between bronchial inflammation and LABC using bronchoalveolar lavage and the PSB technique, showed that the recruitment and activation of neutrophils and eosinophils is a characteristic of CB and is associated with $S$. pneumoniae colonization of the lower airway [32]. In the same study RiISE et al. [32] also found no differences in the LABC pattern of patients with chronic obstructive pulmonary disease (COPD) and patients with nonobstructive $\mathrm{CB}$.

No association was found between airflow obstruction and LABC in stable CB patients in the present study, despite the demonstration of a minimal association between FVC and colonization (OR 0.73). Patients with a low FVC seem to have a higher probability of being colonized, but this effect is much less important than the effect of current smoking. The lack of an association between FEV1 and colonization in this study confirms that COPD is not a major determinant of $\mathrm{LABC}$ when the obstructive pattern is light-to-moderate and the patient does not require exacerbation-related hospital admissions.

In conclusion, lower airway bacterial colonization is present in about one-quarter of stable chronic bronchitis outpatients and current smoking is a risk factor for such colonization. Lower airway bacterial colonization may play a role in the course of $\mathrm{CB}$ in smokers, but this hypothesis must be assessed through longitudinal studies.

Acknowledgements. The authors thank M.E. Kerans and S. Alonso for help in preparing the manuscript, and M.T. Artés for statistical advice.

\section{References}

1. Tager I, Speizer FE. Role of infection in chronic bronchitis. New Engl J Med 1975; 292: 563-571.

2. Fagon JY, Chastre J, Trouillet JL, et al. Characterization of distal bronchial microflora during acute exacerbation of chronic bronchitis. Use of the protected specimen brush technique in 54 mechanically ventilated patients. Am Rev Respir Dis 1990; 142: 1004-1008.

3. Martinez JA, Rodriguez E, Bastida T, Bugés J, Torres M. Quantitative study of the bronchial bacterial flora in acute exacerbations of chronic bronchitis. Chest 1994; 105: 976.

4. Monsó E, Ruiz J, Rosell A, et al. Bacterial infection in chronic obstructive pulmonary disease. A study of stable and exacerbated outpatients using the protected specimen brush. Am J Respir Crit Care Med 1995; 152: 1316-1320.

5. Riise GC, Larsson P, Jeansson S, Andersson BA. The intrabronchial microbial flora in chronic bronchitis patients: a target for $N$-acetylcysteine therapy? Eur Respir J 1994; 7: $94-101$
6. Wimberley NW, Bass JB, Boyd BW, Kirkpatrick MB, Serio RA, Pollock HM. Use of a bronchoscopic protected brush for the diagnosis of pulmonary infections. Chest 1982; 81: 556-562.

7. Wimberley N, Faling LJ, Bartlett JG. A fiberoptic bronchoscopy technique to obtain uncontaminated lower airway secretions for bacterial culture. Am Rev Respir Dis 1979; 119: 337-343.

8. Definition and classification of chronic bronchitis for clinical and epidemiological purposes. Lancet 1965; ii: 775-785.

9. Balows A, Hausler WJ, Herrmann KL, Isenberg HD, Shadomy HJ. Manual of Clinical Microbiology, 5th Edn. Washington DC, American Society of Microbiology, 1991.

10. Murphy TF, Sethi S. Bacterial infection in chronic obstructive pulmonary disease. Am Rev Respir Dis 1992; 146: 1067-1083.

11. Murphy TF, Apicella MA. Nontypable Haemophilus influenzae: a review of clinical aspects, surface antigens, and the human immune response to infection. Rev Infect Dis 1987; 9: 1-15.

12. Feldman C, Smith C, Kaka S, DeJong P, Promnitz DA. The clinical significance of Haemophilus influenzae and $H$. parainfluenzae isolated from the sputum of adult patients at an urban general hospital. S Afr Med J 1992; 81: 495-498.

13. Phillips H, VanHook CJ, Butler T, Mark Tood W. A comparison of cefpodoxime proxetil and cefaclor in the treatment of acute exacerbation of COPD adults. Chest 1993; 104: 1387-1392.

14. Rosen MJ. Treatment of exacerbations of COPD. Am Fam Phys 1992; 45: 693-697.

15. Lentino JR, Lucks DA. Nonvalue of sputum culture in the management of lower respiratory tract infections. J Clin Microbiol 1987; 25: 758-762.

16. Lode H, Schaberg M, Raffenberg M, Mauch H. Diagnostic problems in lower respiratory tract infections. $J$ Antimicrob Chemother 1993; 32: 29-37.

17. Chaste J, Viau F, Brun P, et al. Prospective evaluation of the protected specimen brush for the diagnosis of pulmonary infections in ventilated patients. Am Rev Respir Dis 1984; 130: 924-929.

18. Chastre J, Fagon JY, Bornet-Lecso M, et al. Evaluation of bronchoscopic techniques for the diagnosis of nosocomial pneumonia. Am J Respir Crit Care Med 1995; 152: $231-240$

19. Marquette CH, Herengt F, Mathieu D, Saulnier F, Courcol $\mathrm{R}$, Ramon P. Diagnosis of pneumonia in mechanically ventilated patients. Am Rev Respir Dis 1993; 147: 211214.

20. Marquette $\mathrm{CH}$, Herengt F, Saulnier F, et al. Protected specimen brush in the assessment of ventilator-associated pneumonia. Chest 1993; 103: 243-247.

21. Timsit JF, Misset B, Francoual S, Goldstein FW, Vaury P, Carlet J. Is protected specimen brush a reproducible method to diagnose ICU-acquired pneumonia? Chest 1993; 104: 104-108.

22. Groeneveld K, Eijk PP, Van Alphen L, Jansen HM, Zanen HC. Haemophilus influenzae infections in patients with chronic obstructive pulmonary disease despite specific antibodies in serum and sputum. Am Rev Respir Dis 1990; 141: 1316-1321.

23. Groeneveld K, Van Alphen L, Eijk PP, Visschers G, Jansen HM, Zanen HC. Endogenous and exogenous reinfections by Haemophilus influenzae in patients with chronic obstructive pulmonary disease: the effect of 
antibiotic treatment on persistence. $J$ Infect Dis 1990; 161: 512-517.

24. Lomholt H, Van Alphen L, Kilian M. Antigenic variation of immunoglobulin $\mathrm{A}_{1}$ proteases among sequential isolates of Haemophilus influenzae from healthy children and patients with chronic obstructive pulmonary disease. Infect Immun 1993; 61: 4575-4581.

25. Van Alphen L, Jansen HM, Dankert J. Virulence factors in the colonization and persistence of bacteria in the airways. Am J Respir Crit Care Med 1995; 151: 2094 2099.

26. Irwin RS, Erickson AD, Pratter MR, et al. Prediction of tracheobronchial colonization in current cigarette smokers with chronic obstructive bronchitis. J Infect Dis 1982; 145: 234-241.

27. Del Donno M, Pavia D, Agnew JE, Lopez-Vidriero MT, Clarke SW. Variability and reproducibility in the measurement of tracheobronchial clearance in healthy subjects and patients with different obstructive lung diseases. Eur Respir J 1988; 1: 613-620.

28. Vastag E, Matthys H, Köhler D, Gronbeck L, Daikeler G.
Mucociliary clearance and airways obstruction in smokers, ex-smokers and normal subjects who never smoked. Eur J Respir Dis 1985; 66: Suppl. 139, 93-100.

29. Goodman RM, Yewrgin BM, Landa JF, Golinvaux MH, Sackner MA. Relationship of smoking history and pulmonary function tests to tracheal mucous velocity in nonsmokers, young smokers, ex-smokers, and patients with chronic bronchitis. Am Rev Respir Dis 1978; 117: 205214.

30. Widdicombe J. Relationships among the composition of mucus, epithelial lining liquid, and adhesion of microorganisms. Am J Respir Crit Care Med 1995; 151: 2088-2093.

31. Riise GC, Larsson S, Lofdahl CG, Andeersson BA. Circulating cell adhesion molecules in bronchial lavage and serum in COPD patients with chronic bronchitis. Eur Respir J 1994; 7: 1673-1677.

32. Riise GC, Ahlstedt S, Larsson S, et al. Bronchial inflammation in chronic bronchitis assessed by measurement of cell products in bronchoalveolar lavage fluid. Thorax 1995; 50: 360-365. 